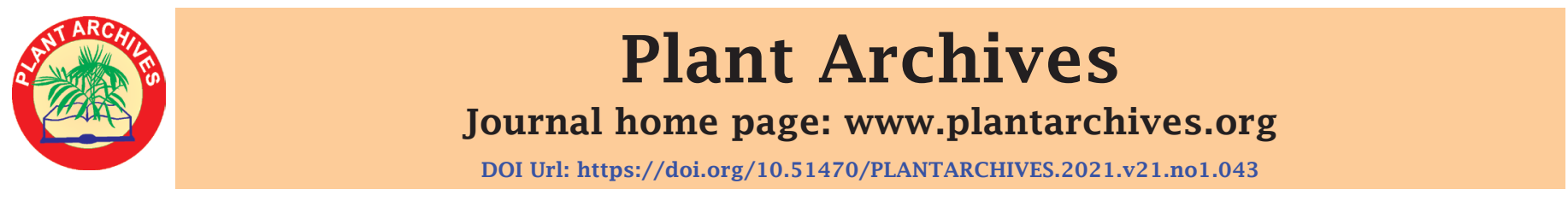

\title{
MANAGEMENT OF FUSARIUM SPECIES ISOLATED FROM ZINGIBER OFFICINALE (GINGER) BY ESSENTIAL OILS
}

\author{
Sumalatha, P and P. K. Maheshwar* \\ Department of Microbiology, Yuvaraja's College, University of Mysore, Karnataka, India. 0821-2419292 \\ *E-mail: pkmaheshwar@ycm.uni-mysore.ac.in \\ (Date of Receiving-06-10-2020; Date of Acceptance-03-01-2021)
}

\begin{abstract}
Mycological examination of 57 samples of Ginger revealed the occurrence of toxigenic Fusarium species (Fusarium verticililoides,
F. oxysporum, F. solani and F. equiseti) with $44.9 \%$ of incidence. Fusarium species isolated in this study were treated with
different concentration (1000 ppm, $1500 \mathrm{ppm}, 2000 \mathrm{ppm}, 2500 \mathrm{ppm}$ ) of five essential oils viz., Clove, Eucalyptus, Cedar wood,
Peppermint and Lemon grass and the antifungal activity of each essential oils was evaluated. The results indicated that all essential
oils exhibited anti-fungal activity at different concentrations. Peppermint oil was highly effective in inhibiting all the Fusarium
species tested at $1500 \mathrm{ppm}$ and higher concentration. Lemongrass, Clove and Eucalyptus oils inhibited the fungal growth at
2000-2500 ppm. Cedar oil was less effective in inhibition of mycelial growth and sporulation of the Fusarium species tested.
The present results reveals that essential oils can be used as natural fungicide at lowest concentrations for controlling Fusarium
species in Ginger
Keywords: Fusarium verticillioides, antifungal activity, essential oil, mycotoxins
\end{abstract}
\section{INTRODUCTION}

Ginger (Zingiber officinale) is a herbaceous perennial, grown for its aromatic rhizomes, used as a spice and medicine (Ramteke and Kamble, 2011). They play an important role in human nutrition and health. Pharmaceutical, perfumery and cosmetic industry also makes extensive use of these plant products. Zingiber oficinale is vulnerable to microbial contaminaton during pre and postharvest handling. Fungal species belonging to Fusarium, Aspergillus and Penicillium are majorly responsible for chemical, nutritional changes and mycotoxin contamination (Adebayo-Tayo et al., 2012). Mycotoxigenic fungi infected to agricultural commodities can lead to reduced quality, yield reduction and mycotoxicosis among humans and livestock. The management of mycotoxigenic fungi and their subsequent mycotoxins is necessary for sustainable, safe food and feed production. The major problem in many countries is the reduction of mycotoxin contamination in agricultural commodities and various preventive measures also have been established for the same in a variety of settings: before harvest and after harvest (in storage, transportation, or processing). All pre-harvest strategies aim to avoid the development mycotoxins and post-harvest practices target to detoxify mycotoxin produced (Luo et al., 2018).

Synthetic fungicides and chemical preservatives play a significant role in controlling mycotoxigenic fungi , but studies on their toxicity indicates that they cause adverse effect on humans, animals and non-target organisms (Mesnage et al., 2014) and negative impact on environment (da Cruz et al., 2013). These factors have resulted in increased search for alternatives to conventional fungicides for effective management of mycotoxigenic fungi (Gakuubi et al., 2017). Non-chemical processes based on plant extracts and secondary metabolites including essential oils, flavonoids, phenols, tannins, alkaloids, quinons, saponins and sterols for the treatment of microbial infection have played an important role in inhibiting pathogen growth and thus improving food quality (Mossini et al., 2004; Amini et al., 2012; Anjorin et al., 2013). Essential oils are a rich source of biologically active compounds and they are potential sources of novel antimicrobial compounds (Adjou et al., 2012). Many scientific studies have shown that essential oils obtained from various parts of plants have antimicrobial activity against many fungal pathogens. They can be used in integrated pest management programs as they are biodegradable compounds and are classified as "generally recognized as safe" (GRAS) by Food and Drug Administration (FDA) (Perczak et al., 2019a).

In the present study Ginger samples were collected from various districts of Karnataka state, India and subjected to mycological examination. Fusarium species isolated from Ginger were tested with different concentrations of essential oils and observed for inhibition of mycelial growth. This study has pivotal role in determining and controlling the mycotoxigenic fungal isolates associated with ginger and ginger derived products.

\section{MATERIALS AND METHODS}

Sampling area: Fifty seven (57) Ginger samples were collected from southern districts of Karnataka state, India

Sources of Essential Oils: Essential oils 
Table-1: Statistical analysis of Essential oils by t-test.

\begin{tabular}{|c|c|c|c|c|c|}
\hline Essential Oils & \#Conc in ppm & F.vert colony $(\mathrm{cm})$ & F.oxy colony $(\mathrm{cm})$ & F.sol colony $(\mathrm{cm})$ & F.equi colony $(\mathrm{cm})$ \\
\hline \multirow{5}{*}{ Clove } & Control & $6.0 \pm 0.17$ & $6.5 \pm 0.06$ & $5.2 \pm 0.25$ & $6.7 \pm 0.21$ \\
\hline & 1000 & $5.8 \pm 0.06^{\mathrm{NS}}$ & $4.9 \pm 0.06^{\mathrm{c}}$ & $2.5 \pm 0.06^{\mathrm{c}}$ & $5.2 \pm 0.06^{\mathrm{c}}$ \\
\hline & 1500 & $5.2 \pm 0.15^{b}$ & $1.0 \pm 0.00^{\mathrm{c}}$ & $2.4 \pm 0.26^{\mathrm{c}}$ & $1.5 \pm 0.06^{\mathrm{c}}$ \\
\hline & 2000 & $2.2 \pm 0.15^{\mathrm{c}}$ & $0.5 \pm 0.00^{\mathrm{c}}$ & $1.1 \pm 0.06^{\mathrm{c}}$ & $0.6 \pm 0.06^{c}$ \\
\hline & 2500 & $0.6 \pm 0.15^{\mathrm{c}}$ & $0.5 \pm 0.00^{\mathrm{c}}$ & $1.0 \pm 0.06^{\mathrm{c}}$ & $0.5 \pm 0.06^{\mathrm{c}}$ \\
\hline \multirow{5}{*}{ Eucalyptus } & Control & $5.8 \pm 0.25$ & $6.5 \pm 0.06$ & $5.2 \pm 0.25$ & $6.6 \pm 0.38$ \\
\hline & 1000 & $1.8 \pm 0.10^{c}$ & $2.7 \pm 0.12^{\mathrm{c}}$ & $1.8 \pm 0.00^{\mathrm{c}}$ & $1.8 \pm 0.15^{\mathrm{c}}$ \\
\hline & 1500 & $1.4 \pm 0.17^{\mathrm{c}}$ & $1.1 \pm 0.10^{\mathrm{c}}$ & $1.6 \pm 0.23^{\mathrm{c}}$ & $1.0 \pm 0.06^{\mathrm{c}}$ \\
\hline & 2000 & $1.2 \pm 0.25^{\mathrm{c}}$ & $1.1 \pm 0.15^{\mathrm{c}}$ & $1.5 \pm 0.17^{\mathrm{c}}$ & $0.5 \pm 0.06^{\mathrm{c}}$ \\
\hline & 2500 & $1.0 \pm 0.00^{\mathrm{c}}$ & $0.9 \pm 0.10^{\mathrm{c}}$ & $0.9 \pm 0.06^{\mathrm{c}}$ & $0.5 \pm 0.00^{\mathrm{c}}$ \\
\hline \multirow{5}{*}{ Cedar } & Control & $6.5 \pm 0.40$ & $6.5 \pm 0.06$ & $5.7 \pm 0.10$ & $6.6 \pm 0.38$ \\
\hline & 1000 & $6.2 \pm 0.10^{\mathrm{NS}}$ & $6.3 \pm 0.15^{\mathrm{NS}}$ & $5.5 \pm 0.06^{\mathrm{a}}$ & $5.3 \pm 0.32^{\mathrm{a}}$ \\
\hline & 1500 & $5.0 \pm 0.10^{\mathrm{c}}$ & $6.0 \pm 0.10^{c}$ & $5.1 \pm 0.10^{\mathrm{b}}$ & $4.3 \pm 0.12^{\mathrm{c}}$ \\
\hline & 2000 & $3.6 \pm 0.20^{\mathrm{c}}$ & $5.0 \pm 0.10^{c}$ & $4.6 \pm 0.15^{\mathrm{c}}$ & $4.1 \pm 0.15^{\mathrm{c}}$ \\
\hline & 2500 & $2.7 \pm 0.12^{\mathrm{c}}$ & $3.4 \pm 0.06^{\mathrm{c}}$ & $4.3 \pm 0.25^{\mathrm{c}}$ & $3.4 \pm 0.10^{\mathrm{c}}$ \\
\hline \multirow{5}{*}{ Lemongrass } & Control & $5.8 \pm 0.10$ & $6.6 \pm 0.06$ & $5.7 \pm 0.26$ & $7.4 \pm 0.20$ \\
\hline & 1000 & $2.5 \pm 0.12^{\mathrm{c}}$ & $2.5 \pm 0.12^{\mathrm{c}}$ & $4.8 \pm 0.15^{b}$ & $1.9 \pm 0.06^{\mathrm{c}}$ \\
\hline & 1500 & $2.1 \pm 0.10^{\mathrm{c}}$ & $2.1 \pm 0.10^{\mathrm{c}}$ & $2.9 \pm 0.15^{\mathrm{c}}$ & $1.2 \pm 0.06^{\mathrm{c}}$ \\
\hline & 2000 & $0.7 \pm 0.06^{\mathrm{c}}$ & $0.7 \pm 0.06^{\mathrm{c}}$ & $1.6 \pm 0.06^{\mathrm{c}}$ & $0.5 \pm 0.00^{\mathrm{c}}$ \\
\hline & 2500 & $0.5 \pm 0.00^{\mathrm{c}}$ & $0.5 \pm 0.00^{\mathrm{c}}$ & $1.2 \pm 0.10^{\mathrm{c}}$ & $0.5 \pm 0.00^{\mathrm{c}}$ \\
\hline \multirow{5}{*}{ Peppermint } & Control & $5.8 \pm 0.10$ & $6.6 \pm 0.06$ & $5.7 \pm 0.26$ & $7.4 \pm 0.20$ \\
\hline & 1000 & $1.1 \pm 0.10^{\mathrm{c}}$ & $3.6 \pm 0.06^{\mathrm{c}}$ & $1.5 \pm 0.12^{\mathrm{c}}$ & $4.6 \pm 0.10^{c}$ \\
\hline & 1500 & $0.5 \pm 0.00^{\mathrm{c}}$ & $1.5 \pm 0.10^{\mathrm{c}}$ & $1.2 \pm 0.12^{\mathrm{c}}$ & $0.5 \pm 0.06^{\mathrm{c}}$ \\
\hline & 2000 & $0.5 \pm 0.00^{c}$ & $0.5 \pm 0.00^{\mathrm{c}}$ & $0.5 \pm 0.00^{\mathrm{c}}$ & $0.5 \pm 0.00^{c}$ \\
\hline & 2500 & $0.5 \pm 0.00^{\mathrm{c}}$ & $0.5 \pm 0.00^{\mathrm{c}}$ & $0.5 \pm 0.00^{\mathrm{c}}$ & $0.5 \pm 0.00^{c}$ \\
\hline
\end{tabular}

Ns; not significant, ${ }^{\mathrm{a}} \mathrm{p}<0.05,{ }^{\mathrm{b}} \mathrm{p}<0.005,{ }^{\mathrm{c}} \mathrm{p}<0.0005$

Abbreviations: \#Conc- Concentration, F.vert- Fusarium verticillioides, F.oxy- Fusarium oxysporum, F.sol- Fusarium solani, F. equi- Fusarium equiseti.

(Eucalyptus, clove, lemon grass and peppermint) were collected at Natural and essential oils limited, Mysore, Karnataka. Cedar wood oil was purchased from Karnataka Aromas, Bangalore, India.

Test Isolates: Fusarium species viz., Fusarium verticillioides, F. oxysporum, F.equiseti F. solani were isolated from Ginger samples by agar plate method and blotter method. The isolated Fusarium colonies were pure cultured and identified based on micro morphological characteristics using fungal keys and manuals (Leslie and
Summerell, 2006). Fusarium isolates were confirmed PCR amplification using universal ITS primers.

Determination of antifungal activity of essential oils: Antifungal activity of each essential oil was determined by Poisoned food technique (Gakuubi et al., 2017). Four different concentrations of five essential oils eucalyptus, clove, lemongrass, peppermint, cedar oils was prepared by incorporating $20 \mathrm{ml}$ of PDA medium with requisite quantity of each oil separately to prepare concentrations of 1000 , 1500,2000 and $2500 \mathrm{ppm} 0.05 \%$ (v/v) Tween 80 was added 
as an emulsifying agent. Agar disk $(0.5 \mathrm{~cm})$ was taken from periphery of five-day-old culture of each Fusarium isolate and inoculated on to the centre of the agar plate and incubated at $25 \pm 2{ }^{\circ} \mathrm{C}$ light and dark for 12 hours each up to 5 days. Three replicates were maintained for each treatment and control set consisted of PDA fungal culture medium without adding any essential oils. The inhibitory effect was evaluated by measuring fungal colony diameter with the help of centimeter scale and compared with control. The diameter of the initial disk was recorded as $(0.5 \mathrm{~cm})$ in case of full inhibition of fungal colony and it was considered as Minimum inhibitory concentration (MIC) et al, 2011).

Statistical analysis: Statistical interpretation of the results was made using $\mathrm{t}$ - test and the differences between concentration used and Fusarium species tested was determined by three way ANOVA test (oil v/s concentrations $\mathrm{v} / \mathrm{s}$ organism). Tukey's multiple comparison tests $(\mathrm{p}=0.05)$ was applied in case of a significant impact to identify the effectiveness of various concentrations against fungal species.

\section{RESULTS AND DISCUSSION}

The efficacy of five essential oils tested against isolated Fusarium species namely $F$. verticillioides, $F$. solani, F. oxysporum, and F. equiseti and statistical analysis was performed (Table 1 and 2). T-test analysis was carried out by comparing control with essential oil treated fungi and the results revealed that all the Fusarium species were significantly reduced by Peppermint, Eucalyptus and Lemongrass oils compared to Clove and Cedar oils (Figure:1). Inhibitory effect of essential oils was directly proportional to the concentration used except for Cedar oil. Minimum inhibitory concentration (MIC) for $F$. verticillioides was found to be 2500ppm for Clove and Eucalyptus, $2000 \mathrm{ppm}$ for Lemongrass and 1500ppm for Peppermint oil. MIC for F. oxysporum was 2000ppm for Clove, Lemongrass and Peppermint oils, $2500 \mathrm{ppm}$ for Eucalyptus oil. MIC for F. solani was observed at $2500 \mathrm{ppm}$ and $2500 \mathrm{ppm}$ using Eucalyptus and Peppermint oil respectively, where as other essential oils did not show significant inhibition. MIC for $F$. equiseti was recorded at 2000 ppm using Lemongrass, Clove, Eucalyptus and 1500 ppm with Peppermint oil. Cedar oil was not effective in inhibiting the mycelial growth irrespective of oil concentrations.

Multiple comparison analysis using Tukey's test revealed that all the essential oils tested were effective in reducing mycelial growth and spore germination at various concentrations. At lower concentrations of $1000 \mathrm{ppm}$ Eucalyptus oil reduced the growth of $F$. verticillioides and F.solani compared to other species whereas Clove oil was effective in reducing the mycelial growth at 2000 and 2500 ppm for $F$. oxysporum and $F$. equiseti. The inhibitory effect of Lemon grass was observed for $F$. verticillioides , F.oxysporum and F. equiseti. The Peppermint oil was more effective for $F$. verticillioides and F.equiseti at various concentrations.Cedar oil was less effective in reducing the mycelial growth compared to other oils but did not inhibit the fungal growth completely.

Lemongrass, Eucalyptus and Peppermint oils were found to be very effective in inhibiting all of the Fusarium species tested at different concentrations and this complies with the earlier findings of the research group who pointed out that essential oils from citronella, peppermint, lemongrass, and clove are effective against many Fusarium species (Sreenivasa et al., 2011). The inhibitory potential of Clove, Lemongrass and Eucalyptus against $F$. oxysporum was recorded at very lower concentrations from 125 ppm-500ppm (Sharma et al., 2017). Among seventy five essential oils screened, $F$. oxysporum was sensitive to most of the essential oils. Lemongrass was most effective and Clove was less effective to F. oxysporum (Pawar and Thaker, 2007). In contrast, studies conducted elsewhere reported that Clove has antimicrobial and antifungal properties against Fusarium species (Massoud et al., 2012; Deng et al., 2013; Thabet and Khalifa ,2018). Fusarium solani and F. oxysporum can be inhibited by leaf extracts and essential oils of Eucalyptus respectively ( Bashir and Tahira, 2012; Regmi and Jha, 2018). Inhibition of $98 \%$ of spore germination of F.verticillioides, F.oxysporum and F.solani by Eucalyptus oil was observed at 500ppm (Elgorban et al., 2015). The effects of twelve essential oils on F.oxysporum and compared with commercial fungicides was examined and found that fungicide Prosaro -250 EC and essential oils from clove, fennel, anise, true lavender, peppermint, thyme, basil, tea and sage exhibited the same inhibitory effect (Palfi et al ., 2019). The inhibition of F.graminearum and F. culmorum in maize and wheat seeds and reduction in the Deoxynivalenol, zearalenone and group B trichothecenes level with the application of essential oils was reported ( Perczak et al., 2019a; 2019b). Kumar et al. (2016) reported the inhibition of growth and mycotoxin (ZEA) production by Fusarium graminearum at 3.5 and $3 \mathrm{mg} / \mathrm{mL}$ respectively by turmeric essential oil. Another study revealed that wild oregano and garlic essential oils completely prevented the growth of Penicillium verrucosum and its mycotoxin production, while mint and sage essential oils significantly reduced the OTA production by Penicillium verrucosum (Ozcakmak et al ., 2017).

The present work reveals that Ginger has the potential to harbor toxigenic Fusarium verticillioides in significant numbers, which is capable of producing mycotoxin which causes many health hazards to humans. Ginger is consumed raw and used in ayurvedic medicine which causes adverse effects on consumer's health, hence appropriate control measures must be taken to avoid fungal contamination. This can be made possible by using biologically safe natural fungicides like essential oils. In our study all the tested essential oils were capable of reducing and inhibiting the growth of F.verticillioides, F.oxysporum, F.solani and $\quad F$.equiseti at various concentrations and the results were completely dependent upon the concentration and type of essential oil used. Peppermint, Eucalyptus , Lemongrass, and Clove oils exhibited antifungal activity 
Table-2 Statistical analysis by Tukey's multiple comparison test.

\begin{tabular}{|c|c|c|c|c|c|c|c|}
\hline Essential Oils & \#Conc in ppm & F ver vs F oxy & F ver vs F sol & F ver vs F equ & F oxy vs F sol & F oxy vs F equ & F sol vs F equ \\
\hline \multirow{4}{*}{ Clove } & 1000 & $* *$ & $* *$ & $* *$ & $* *$ & $* *$ & $* *$ \\
\hline & 1500 & $* *$ & $* *$ & $* *$ & $* *$ & $*$ & $* *$ \\
\hline & 2000 & $* *$ & $* *$ & $* *$ & $* *$ & NS & $* *$ \\
\hline & 2500 & NS & $* *$ & NS & $* *$ & NS & $* *$ \\
\hline \multirow{4}{*}{ Eucalyptus } & 1000 & $* *$ & NS & NS & $* *$ & $* *$ & NS \\
\hline & 1500 & NS & NS & NS & $*$ & NS & $* *$ \\
\hline & 2000 & NS & NS & $* *$ & NS & $*$ & $* *$ \\
\hline & 2500 & NS & NS & $* *$ & NS & $* *$ & $* *$ \\
\hline \multirow{4}{*}{ Cedar } & 1000 & NS & $* *$ & $* *$ & $* *$ & $* *$ & NS \\
\hline & 1500 & $* *$ & NS & $* *$ & $* *$ & $* *$ & $* *$ \\
\hline & 2000 & $* *$ & $* *$ & $*$ & NS & $* *$ & $*$ \\
\hline & 2500 & $* *$ & $* *$ & $* *$ & $* *$ & NS & $* *$ \\
\hline \multirow{4}{*}{ Lemongrass } & 1000 & NS & $* *$ & $* *$ & $* *$ & $* *$ & $* *$ \\
\hline & 1500 & NS & $* *$ & $* *$ & $* *$ & $* *$ & $* *$ \\
\hline & 2000 & NS & $* *$ & $*$ & $* *$ & $*$ & $* *$ \\
\hline & 2500 & NS & $* *$ & NS & $* *$ & NS & $* *$ \\
\hline \multirow{4}{*}{ Peppermint } & 1000 & $* *$ & $* *$ & $* *$ & $* *$ & $* *$ & $* *$ \\
\hline & 1500 & $* *$ & $* *$ & NS & $*$ & $* *$ & $* *$ \\
\hline & 2000 & NS & NS & NS & NS & NS & NS \\
\hline & 2500 & NS & NS & NS & NS & NS & NS \\
\hline
\end{tabular}

Ns; not significant, ${ }^{*} \mathrm{p}<0.05,{ }^{* *} \mathrm{p}<0.01$

Abbreviations: \#Conc-Concentration, F.ver-F.verticillioides, F.oxy-F. oxysporum, F. sol-F.solani, F. equ-F. equiseti

hence use of these oils can increase the shelf life of ginger and can overcome losses caused during storage conditions. MIC reported as low as $1000 \mathrm{ppm}$ indicates the economy of essential oils as the fungal growth is inhibited in minute concentrations, economic burden is reduced. Essential oils as natural fungicide plays significant role over biological and environmental complications caused by synthetic fungicides. Therefore these essential oils are superior and ecofriendly, in view of this the authors urge concerned authority to implement laws and perpetuate the information among farmers and store keepers to apply essential oils to Ginger, a highly perishable commodity thus avoiding economical as well as health hazards.

\section{ACKNOWLEDGEMENT}

First author acknowledges the research support provided by Department of Microbiology, Yuvaraja's College and Manasagangothri, University of Mysore, Karnataka, India.

\section{REFERENCES}

Adebayo-Tayo, B.C., N.N. Odu, C.U. Esen, and I.O. Oconto (2012). Microorganisms associated with spoilage of stored vegetables In Uyo Metropolis, Akwa Ibom State, Nigeria. Nature and Science, 10:23-32.

Adjou, E. S., S. Kouton, E. Dahouenon-Ahoussi, D. C. K. Sohounhloue andM.M. Soumanou (2012). Antifungal activity of Ocimum canum essential oil against toxinogenic fungi isolated from Peanut Seeds in post-harvest in Benin. International Research Journal of Biological Sciences, 1:20-26.

Amini, M., N. Safaie, M.J. Salmani and M. Shams-Bakhsh (2012). Antifungal activity of three medicinal plant essential oils against some phytopathogenic fungi. Trakia journal of sciences, 2012,10:1-8.

Anjorin, T.S., E.A. Salako and H.A. Makun (2013). Control of toxigenic fungi and mycotoxins with phytochemicals: potentials and challenges in Mycotoxin and Food Safety in Developing Countries 
,edited by HA Makun (InTech,

Croatia), 181-202.

Bashir, U. and J. J. Tahira (2012). Evaluation of Eucalyptus camaldulensis against Fusarium solani. International Journal of Agriculture and Biology, 14: 675-677.

da Cruz, C.L., V.F. Pinto and A. Patriarca (2013) .Application of plant derived compounds to control fungal spoilage and mycotoxin production in foods. International Journal of Food Microbiology, 166:1-14.

Deng, J., Wen Li, X. Lin Peng and X. H. Hao (2013).Study on the potential of antifungal activity of essential oils against fungal pathogens of fruits and vegetables. Journal of chemical and pharmaceutical research, 5:443-446.

Elgorban, A. M., A. H. Bahkali, M. A. El-Metwally, M. Elsheshtawi and M.A. AbdelWahab (2015). Invitro antifungal activity of some plantessentialoils. International Journal of Pharmacology, 11:56-61.

Gakuubi, M.M. , A.W. Maina and J. M. Wagacha (2017). Antifungal activity of essential oil of Eucalyptus camaldulensis Dehnh. against selected Fusarium spp. International Journal of Microbiology, 2017:1-7.

Kumar, K.N., M. Venkataramana, J.A. Allen, S. Chandranayaka, H.S. Murali and H. V. Batra (2016). Role of Curcuma longa $L$. essential oil in controlling the growth and zearalenone production of Fusarium graminearum. LWT Food Science and Technology, 69:522-528.

Leslie, J.F. and B.A. Summerell (2006). The Fusarium Laboratory Manual.(1 $\left.{ }^{\text {sted}}\right)$. Blackwell, Ames, Iowa, USA.

Luo, Y., X. Liu and J. Li (2018). Updating techniques on controlling mycotoxins -A review. Food Control, 89: 123132.

Massoud, M. A., A. S. A. Saad, E. A. Soliman and A.Y. ElMoghazy (2012). Antifungal activity of some essential oils applied as fumigants against two stored grains fungi. Academia Journal of Agricultural Research, 17: 296-305.

Mesnage, R., N. Defarge, S.J. de Vendomois and G. E. Seralini (2014). Major pesticides are more toxic to human cells than their declared active principles. BioMed Research International journal, 2014:1-8.

Mossini, S. A., K. P. de Oliveira and C. Kemmelmeier (2004). Inhibition of patulin production by Penicillium expansum cultured with neem(Azadirachta indica) leaf extracts. Journal of Basic Microbiology, 44:106-13.

Ozcakmak, S., O. Gul, M. Dervisoglu, A. Yilmaz, O. Sagdic and M. Arici (2017).Comparison of the effect of some essential oils on the growth of Penicillium Verrucosum and its Ochratoxin A production. Journal of Food Processing and Preservation, 41:1-9.

Palfi, M., P. Konjevoda, K. Vrandecic and J. Cosic (2019). Antifungal activity of essential oils on mycelial growth of Fusarium oxysporum and Bortytis cinerea. Emirates Journal of Food and Agriculture, 31:544-554.

Pawar, V. C. and V. S. Thaker (2007). Evaluation of the anti- Fusarium oxysporum f. sp cicer and antiAlternaria porri effects of some essential oils. World Journal of Microbiology and Biotechnology, 23 :1099-1106.

Perczak, A., D. Gwiazdowska, R. Gwiazdowski, K. Jus, K. Marchwinska and A. Waskiewicz (2019a). Antifungal activity of selected essential oils against Fusarium culmorum and $F$. graminearum and their secondary wheat seeds. Archives of Microbiology, 201:1085-1097.

Perczak, A., D. Gwiazdowska, R. Gwiazdowski, K. Jus, K. Marchwinska and A. Waskiewicz (2019b).The inhibitory potential of selected essential oils on Fusarium spp. growth and mycotoxins biosynthesis in Maize seeds. Pathogens, 9:1-16.

Ramteke, P.K. and S.S. Kamble (2011). Physiological studies in Fusarium solani causing rhizome rot of ginger (Zingiber officinale Rosc.).The Bioscan, 6:195-197.

Regmi, S. and S. K. Jha (2018). Antifungal activity of plant essential oils against Fusarium oxysporum schlecht. and Aspergillus niger van tiegh. from Papaya. International Journal of Current Trends in Science and Technology,8: 20196-20204.

Sharma, A., S. Rajendran, A. Srivastava, S. Sharma and B Kundu (2017). Antifungal activities of selected essential oilsagainst Fusarium oxysporum .sp. lycopersici 1322,with emphasis on Syzygium aromaticum essential oil. Journal of Bioscience and Bioengineering, 123: 308-313.

Sreenivasa, M.Y., R.S. Dass, A.P. Charith Raj, M.N. Nagendra prasad, P.N. Achar and G.R. Janardhana(2011).Assessment of the growth inhibiting effect of some plant essential oils on different Fusarium species isolated from sorghum and maize grains. Journal of Plant Diseases and protection, 118: 208-213.

Thabet, M. and W . Khalifa (2018). Antifungal activities of Clove oil against root rot and wilt pathogens of tomato plants. American-Eurasian journal of agricultural and environmental sciences, $18: 105-114$. 